\title{
Remote sensing in global geoscience processes: Introductory remarks
}

\author{
Important global scale applications in geology \\ can be addressed by the use of the most advanced \\ sensors that are available now on satellites. The \\ articles in this special issue of Episodes have been \\ assembled by the Advisory Board on Remote Sens- \\ ing for the purpose of discussing such applications.
}

\section{Introduction}

$\mathrm{O}_{\text {ne of the primary roles of the Advisory Board on Remote Sensing }}$ (ABRS) of the International Union of Geological Sciences (IUGS) is to facilitate the use of remote sensing data by the international geological community. A 2-day workshop hosted by the ABRS and the University of Colorado in the USA in May 1991 addressed the use of existing and planned remote sensing satellites. This introductory article evolved from the 1991 workshop and presents a starting point for future discussions and for future directions of remote sensing within the IUGS. Included in this special issue of Episodes are more detailed reviews and applications of remote sensing data to global geoscience processes, including geologic hazards.

The degree to which rock units have been mapped on the Earth varies considerably from country to country. Vast areas in developing countries, deserts, and jungles have been mapped only at reconnaissance scales. A better understanding of the characteristics of these rock units would increase our understanding of the deformational history of the Earth, as well as the location and mode of emplacement of nonrenewable resources. A remote sensing approach would provide the synoptic view that is necessary in order to map poorly known areas, and in some cases, remote sensing would provide a detailed view as well.

Although remote sensing is a relatively young scientific discipline, its use in the geosciences over the last two decades has been quite remarkable. Currently operational satellite systems, such as the USA's Landsat and France's SPOT, and radar images from satellites and aircraft are employed widely in geological mapping and exploration programs, as well as in investigations of geologic hazards. Figure 1 shows an example of the extensive use of remote sensing techniques within the international geological community.

In general, three methods are used to extract geological information from remote sensing data. These are the spectral, photogeological, and integration methods. Examples of all these methods are evident in this issue of Episodes. The spectral approach involves the separation of surface materials or vegetation based on spectral reflectance, emittance, or backscatter. This approach is used for analyzing multispectral image data in both vegetated and nonvegetated areas. Laboratory and field spectral data often are employed in order to establish the physical basis for the remote determination of rocks, soils, minerals, or vegetation. The photogeological technique uses topographic expression and image textures for delineating geologic structures and geomorphic and lithologic units. This is a very com- non and effective approach and relies, to a large extent, on the skills of the interpreter. The integration method involves the merging of remote sensing data and geological, geophysical, or topographic information for the purpose of assisting in the interpretation of the spectral or photogeological units and for determining their relationships with the other data sets. This integration approach is being incorporated increasingly in geological remote sensing as more geological and topographic data are available in digital form.

\section{Global land processes}

Several significant developments have taken place in remote sensing in terms of the uses of existing satellites and the capabilities of planned satellites that are directly applicable to the study of geoscience processes. These developments include the higher spatial, spectral, and stereo capabilities that can provide more quantitative measurements of surface and near-surface features for the purpose of predictive modeling. For instance, the techniques developed and sensors used for geological mapping and exploration can be applied to the investigation of crustal and tectonic movements, arid lands, geology, and erosion processes, among others.

For decades, geologists have used remotely sensed images successfully in order to identify primary earth materials (rocks and minerals) and their regolith. The application of high-resolution spectrometers to mineral mapping is rapidly becoming a reality. The use of Landsat Thematic Mapper (TM) and SPOT data, when available, can provide a way to map mineral assemblages in arid and semiarid areas. However, higher spectral resolution clearly would be needed for us to be able to separate most rock types and soils. Nonetheless, the identification of minerals, rocks, soils, and vegetation from laboratory, field, and airborne spectra is a significant development in the study of global geoscience processes. Although valuable geological information has been derived from the spectral data provided by Landsat and SPOT, high-resolution imaging spectrometers have extensive capabilities in spectral geology and for global spectral measurements. Such capabilities are described by Goetz in his article in this issue.

In vegetated areas, however, other methods are needed to detect the variations in vegetation for the purpose of mapping the underlying materials. Developments in geobotanical remote sensing over the past decade have increased our knowledge of the influence of lithology, topography, and geochemistry on the distribution and density of vegetation. Bell and others (abstract in this issue) have shown that an understanding of the relationships between vegetation and lithology can provide additional insights into the distribution of global biomes. Rock (abstract in this issue), Singhroy (1988), and others have used airborne multispectral imagers to locate, monitor, and study forest damage that has resulted from natural mineral concentrations, mine wastes, and other environmental factors. The capability of remote sensing techniques to map and monitor vegetation stress that is caused by both natural and anthropogenic factors is significant in our understanding of the biogeochemical cycle. 


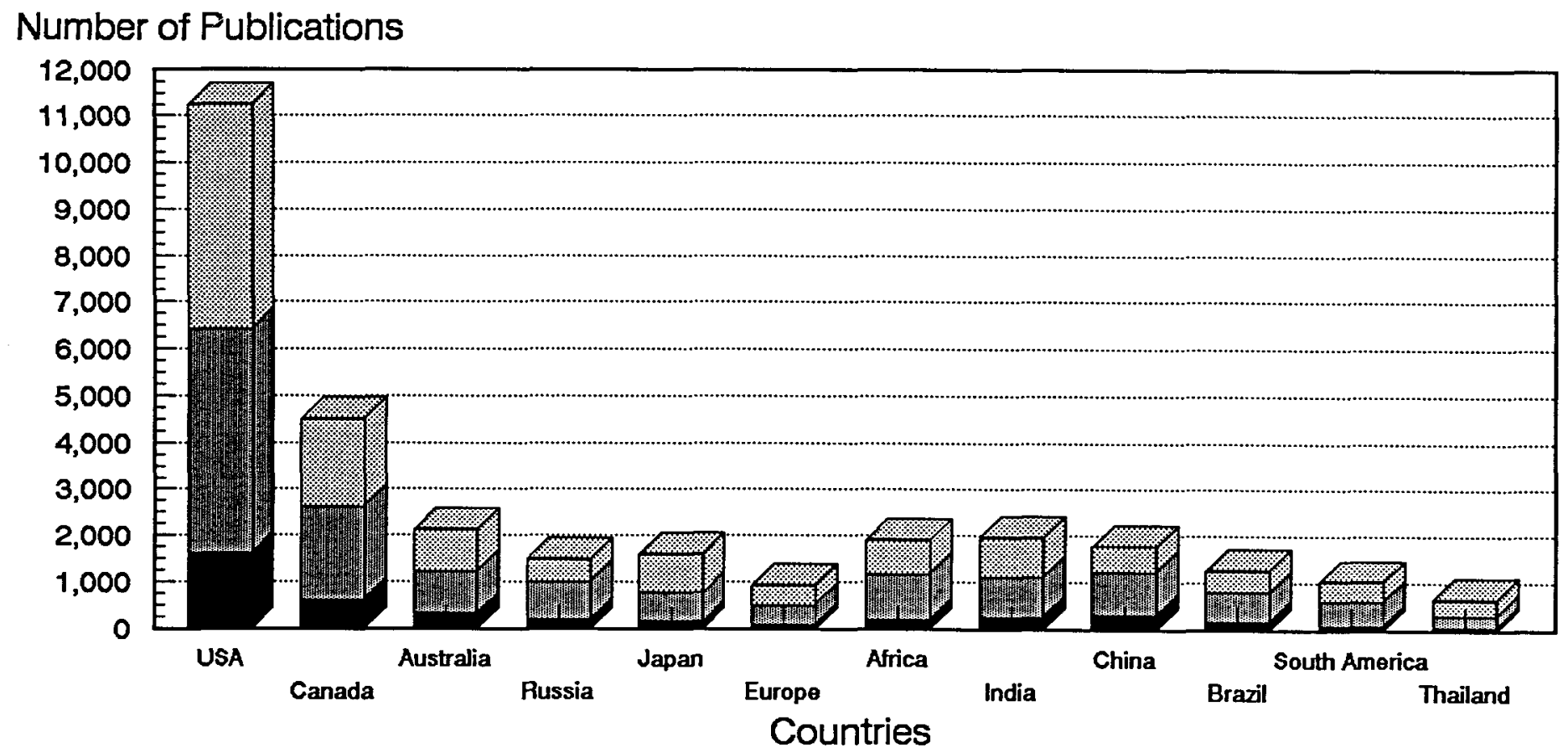

\begin{tabular}{ccccc}
\hline Exploration & Mapping & Geological Hazards & \\
Hydrocarbon & Geological & Erosion & Floods \\
Mineral & Geobotany & Coastal Erosion & Earthquakes \\
& Glaclal & Land Dogradation & Volcanoes \\
& & Landslides &
\end{tabular}

Figure 1.-International applications of geological remote sensing techniques from 1980 to 1991 . Compiled by Canada Centre for Remote Sensing.

The capabilities of Synthetic Aperture Radar (SAR) for landform and geological mapping and for tectonic activity and erosion studies, as well as its potential in providing information on soil moisture, surface roughness, and topography, are described in this issue by Evans and by Singhroy. Because SAR penetrates clouds and sometimes vegetation and thin sand, it can be applied to the study of geologic processes in cloudy, vegetated, and arid areas where other sensors are limited. The use of SAR in characterizing and mapping evidence of alternating humid and arid climates, such as fossil dune fields, paleorivers, and paleolakes, is particularly significant for reconstructing the climatic history of deserts that existed during the Cenozoic (Petit-Maire and others, abstract in this issue).

The development of remote sensing methods for mapping rock units, detecting crustal movements, and monitoring selected surface processes is crucial to predictive modeling. These techniques include the mapping of fracture systems from multispectral satellite and SAR images (Halbouty. 1976, 1980; Misra and others, 1991; Abrams and others, 1985), the statistical analysis of lineament data, and the creation of lineament density maps (Misra and others, 1991). Image enhancement techniques such as principal component analysis (Loughlin, 1991; Chavez and Bowell, 1988), decorrelation stretching of bands (Dury and Hunt, 1988), and band ratios (Podwysocki and others, 1983) are some of the common image processing methods that are used by geoscientists. The integration of geophysical and remote sensing data is being carried out increasingly for geological investigations in different environments (Harris, 1991; FernandezAlonso and Tahon, 1991). Landsat and SPOT, when merged with geographic, geologic, and digital elevation information, have produced revised maps and realistic perspectives of the Earth's surface. Such three-dimensional spatial and dynamic modeling that results from the combination of geographic information systems (GIS) and remote sensing is crucial for geoscience applications.

\section{Geologic hazards}

In the context of the International Decade for Natural Disaster Reduction (IDNDR), remote sensing techniques are playing an increasing role in the identification and monitoring of areas of geologic hazards. In this issue, studies show that satellite and airborne remote sensing and GIS techniques have been used to study volcanic eruption processes, to produce hazard maps in mountainous areas, to monitor landslide activities, and to identify fracture zones associated with seismic activity. These remote sensing techniques can lead to disaster reduction by preventing disasters through measures such as improved construction or land-use practices; by providing warnings and forecasts; and by rendering fast, effective relief after disaster strikes (Walter, abstract in this issue).

Mouginis-Mark and Francis (this issue) review the current applications of the many remote sensing techniques as they apply to the analysis of volcanoes and volcanic terranes. Landsat TM images have been used to map the distribution of volcanic lithologies, to identify potentially active volcanoes and volcanic debris deposits, 
and to monitor lava flows. Images from the Geostationary Operational Environmental Satellite (GOES) and the U.S. National Oceanic and Atmospheric Administration's NOAA 7 satellite have been employed in monitoring the downwind disposal of an eruption plume and in measuring plume temperature. The evolution of a lava flow field and its thermal characteristics can be studied over a period of time by using daily Advanced Very High Resolution Radiometer (AVHRR) satellite images. Under cloudy conditions, the potential is great that SAR data will be able to map the distribution of lava flows, cinder cones, and fault zones. In Japan, regional volcanic framework mapping has been conducted by the use of thermal infrared imagery (Yamaguchi and others, this issue).

The production of hazard maps at various scales from 1:250,000 to $1: 5,000$ has been accomplished by combining remote sensing and GIS techniques in mountainous areas and is described by Rengers and others (this issue). Aerial photographs, SPOT, and Landsat data were processed by the use of GIS, particularly for landslide hazard assessment. In cloudy, tropical, mountainous areas, radar images also will provide information on geologic structures, slopes, and terrain roughness. However, input into GIS could require geometrically corrected radar images.

Leroi and others (this issue) created a digital elevation model from a hybrid SPOT and Landsat stereopair and analyzed slope morphology and debris in relation to landslides in Colombia. The landslide hazard map that resulted from SPOT, Landsat, and GIS techniques is part of the Geological Application of Remote Sensing (GARS) project of the United Nations Educational, Scientific, and Cultural Organization (UNESCO). Similar techniques, described by McKean and others (1991), have employed Landsat TM data in a GIS context for the purpose of exploring the effect of vegetation type on debris flow for use in hazard modeling.

The mapping of fracture systems from several types of remotely sensed data is well documented in seismically active areas (Shibakova and others, this issue; Moon, 1991; and others). Measurements of horizontal terrain displacements associated with earthquakes have been conducted by the use of SPOT imagery (Crippen, this issue). Eliason (this issue) provides a structural analysis of fracture systems that uses topographic and seismic data. This information can be integrated with other satellite lineament maps for the structural interpretation of seismically active areas.

\section{Future directions}

Understanding global geologic and geophysical processes requires a diversity of accurate observations. The need to monitor the mechanisms of geologic hazards, crustal movements, desertification, erosion processes, and sea level changes is fundamental to our understanding the total Earth system, from which we hope to develop a capability to predict future change. The existing and planned satellite systems (fig. 2) and the techniques described in this issue are a means to study global geoscience processes. Of particular interest will be the series of radar satellites to be launched in the $1990 \mathrm{~s}$, such as ERS-1 (Europe), JERS-1 (Japan), and Radarsat (Canada), which will provide geologic information from the Tropics and other parts of the Earth. Clearly, important global scale research in geology is being addressed by using the most advanced sensors now available on satellites, and this research will continue as planned satellites are launched. The IUGS through the ABRS will continue to report on these developments and will encourage cooperative research in geological remote sensing. I hope that discussions resulting from this issue of Episodes will chart the future directions of programs on remote sensing activities within the IUGS.

\section{References}

Abrams, M.J., Conel, J.E., Lang, H.R., and Paley, H.N., 1985, The joint NASA/Geosat test case project, final report: Tulsa, Oklahoma, USA, American Association of Petroleum Geologists, v. 1 and 2, 622 p.

Chavez, P.S., and Bowell, J.A., 1988, Comparison of the spectral information content of Landsat Thematic Mapper and SPOT for three different sites in Phoenix, Arizona, region: Photogrammetric Engineering and Remote Sensing, v. 54, no. 12, p. 1699-1708.

Dury, S.A., and Hunt, G.A., 1988, Remote sensing of laterized Archean greenstone terrain: Marshall Pool area, northeastern Yilgarn Block, Western Australia: Photogrammetric Engineering and Remote Sensing, v. 54, no. 12 , p. $1717-1725$.

Fernandez-Alonso, M., and Tahon, A., 1991, Lithologic discrimination and structural trends in W. Rwanda (Africa) on images of airbone radiometric and aeromagnetic surveys registered to a Landsat TM scene: Photogrammetric Engineering and Remote Sensing, v, 57, no. 9, p. $1155-1162$.

Halbouty, M.T., 1976, Application of Landsat imagery to petroleum and mineral exploration: American Association of Petroleum Geologists Bulletin 60 , p. $745-793$.

-1980, Geologic significance of Landsat data for 15 giant oil and gas fields: American Association of Petroleum Geologists Bulletin 64, p. $8-36$.

Harris, J., 1991, Mapping of regional structure of eastern Nova Scotia using remotely sensed imagery: Implications for regional tectonics and gold exploration: Canadian Journal of Remote Sensing, v. 17, no. 2, p. 122-136.

Loughlin, W.P., 1991, Principal component analysis for alteration mapping: Photogrammetric Engineering and Remote Sensing, v. 57, no. 9, p. $1163-1169$.

McKean, J., Buechel, S., and Gaydos, L., 1991, Remote sensing and landslide hazard assessment: Photogrammetric Engineering and Remote Sensing, v. 57, no. 9, p. 1185-1193.

Misra, K.S., Slaney, V.R., Graham, D., and Harris, J., 1991, Mapping of basement and other tectonic features using Seasat and Thematic Mapper in hydrocarbon-producing areas of the western sedimentary basin of Canada: Canadian Journal of Remote Sensing, v. 17, no. 2, p. 137-151.

Moon, W.M., Won, J.S., Li, B., Slaney, V.R., and Lamontagne, M., 1991, Application of airborne C-SAR and SPOT image data to the geological setting of the Nahanni earthquake area: Canadian Journal of Remote Sensing, v. 17 , no. 3, p. 272-278.

NASA (National Aeronautics and Space Administration), 1990, EOS: A mission to planet Earth: Washington, D.C., USA, p. 6.

Podwysocki, M.H., Segal, D.B., and Abrams, M.J., 1983, Use of multispectral scanner images for assessment of hydrothermal alteration in the Marysvale, Utah, mining area: Economic Geology, v. 78, no. 4, p. $675-687$.

Singhroy, V.H., 1988, An overview of geobotanical remote sensing in Canada, in Howarth, P.J., ed., Canadian Symposium on Remote Sensing, 11 th, Waterloo, Ontario, Canada, 1987, Proceedings, p. 259-275. $\square$ 


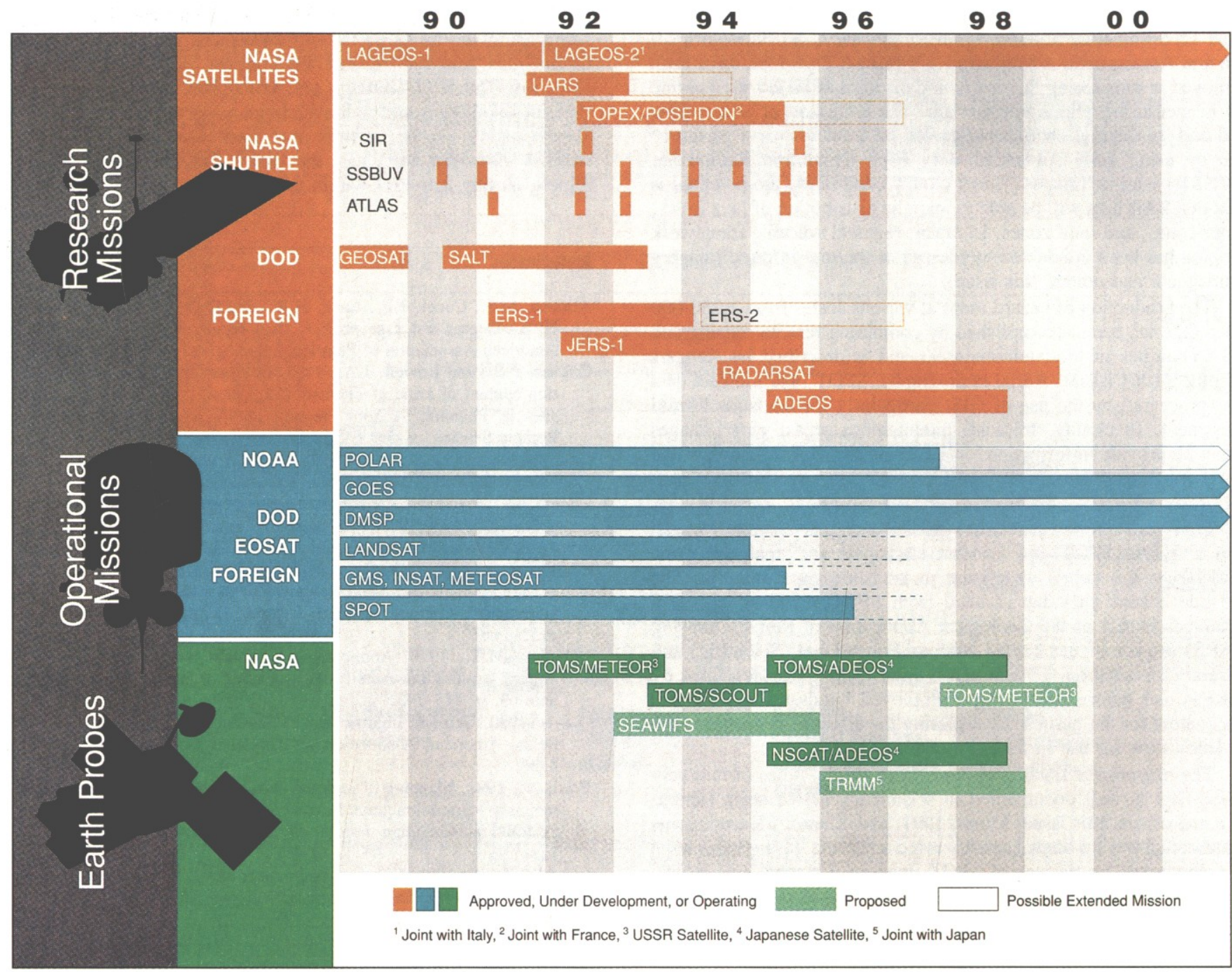

Figure 2.-Existing and planned satellite systems for the years 1988 through 2002. Taken from NASA (1990). Abbreviations: NASA, U.S. National Aeronautics and Space Administration; DOD, U.S. Department of Defense; NOAA, U.S. National Oceanic and Space Administration; EOSAT, Earth Observation Satellite Company, USA.

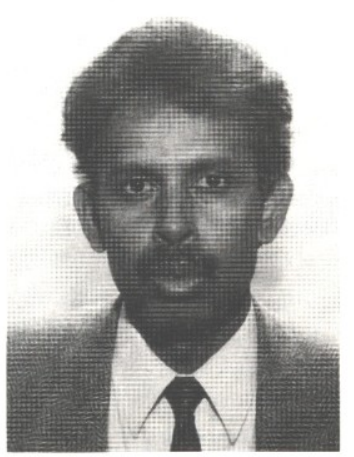

Dr. V.H. Singhroy is Chairman of the Advisory Board on Remote Sensing of the International Union of Geological Sciences, Research Scientist in geological remote sensing, and Scientific Advisor at the Canada Centre for Remote Sensing in Ottawa, Ontario, Canada. 